New Product Approvals

Product

Companies

Fabrazyme

(agalsidase beta)

Genzyme General

(Cambridge, MA)

\begin{tabular}{ll}
$\begin{array}{l}\text { VariZIG } \\
\text { (Varicella zoster } \\
\text { immune globulin) }\end{array}$ & $\begin{array}{l}\text { Cangene } \\
\text { (Winnipeg, } \\
\text { Canada) }\end{array}$ \\
\hline Zomacton & $\begin{array}{l}\text { Bio-Technology } \\
\text { General } \\
\text { (BTG; Iselin, NJ) } \\
\text { Ferring Group } \\
\\
\end{array}$ \\
& (Malmo, Sweden)
\end{tabular}

\section{EU seed production proposals}

The European Commission has outlined draft legislative measures for dealing with the adventitious presence of GM seeds in conventional varieties. According to the working paper, GM material that is covered by the EU directive 90/220, which regulates the deliberate release of GMOs into the environment, should not exceed a threshold of $0.3 \%$ in the case of cross pollinating varieties and $0.5 \%$ in the case of self pollinating and vegetatively propagating crops. (There is zero threshold for GM seeds not authorized under 90/220.) In addition, the Commission wants longer time periods between the planting of non-GM crops on land previously sown with GM plant varieties-two years instead of one for most plants, but five years in the case of plants whose seeds would survive several years (such as fodder plants, and oil and fiber plants). The document also proposes labeling requirements: all packages of seeds must carry "EU-unauthorized genetically modified organisms not present" on the label, and packages of seeds of GM varieties authorized under $90 / 220$ are to be labeled "genetically modified variety." The deadline for government comments on the proposals is April 10.

$E D$

\section{Biotech litmus test}

On January 31, genomic-platform company Exact Sciences (Maynard, MA) completed the first biotech IPO this year, but analysts say the disappointing performance of the offering indicates a market not yet ready for another "biotech boom." Exact raised \$56 million from the sale of 4 million shares at

Details

An enzyme replacement therapy to combat Fabry disease. On January 18, the French Medicines Agency gave Genzyme an Authorisation Temporaire d'utilastion to allow treatment with Fabrazyme before marketing approval by the EMEA, which is expected in the first half of 2001. Fabry disease is a rare, $\mathrm{X}$-linked disorder that can cause progressive, multi-systemic impairment of tissue and organ function, causing death typically around age 40 for the estimated 2,000-4,000 people afflicted worldwide. Fabrazyme has received orphan status in the US, Europe, Japan, and Australia. Transkaryotic Therapies (Cambridge, MA) has requested marketing approval by the FDA and EMEA for its rival drug, Replagel (agalsidase alpha).

A recombinant protein to stimulate hyperimmunity against chicken pox in pregnant women who might be exposed to the virus for the first time. VariZIG received approval in Canada on January 19, and has a potential world market value of $\mathrm{C} \$ 40$ million (\$26.3 million) per year. Massachusetts Public Health Biologic Laboratories (Jamaica Plain, MA) markets a competing immune globulin in the US and Canada.

The EMEA approved on January 8 a recombinant growth hormone to treat Turner's syndrome, to be marketed by Ferring where it already markets the drug to treat pituitary growth hormone deficiency in children. Turner's syndrome affects 1 in 2,000 female babies, causing abnormalities in growth and organ development in females born with only one $\mathrm{X}$ chromosome. Competitors include Genentech's (S. San Francisco, CA) Nutropin and Eli Lilly's (Indianapolis, IN) Humatrope.

$\$ 14$ - the low end of its range-and after its first full week of trading was down $20 \%$ to $\$ 11.31$. This, despite the company's colorectal cancer diagnostic which, scheduled to enter phase III trials in the fourth quarter, has a clear path to relatively near-term profits, according to SG Cowen (Boston, MA) analyst Bill Tanner. He says this indicates that companies wanting to go public but not expecting to be profitable for 4 or 5 years "don't have a prayer right now." Tanner adds that the publishing of the human genome sequence is unlikely to help the situation as investors have become more savvy: "People have figured out that [the time from] sequencing the human genome [to] when there's actually value created is a lot farther away then they originally thought."

\section{US federal antibiotics plans}

The FDA Center for Veterinary Medicine (CVM; Rockville, MD) recently released a draft plan that calls for establishing "regulatory thresholds on antimicrobial resistance" for antibiotics used in agricultural settingssomething that could impact on researchers across the US, Europe, and elsewhere who are sequencing genomes of microbial pathogens as part of an expanded effort to develop new antibiotics. The thresholds described in the draft plan would trigger either "voluntary mitigation" efforts by drug manufacturers and food producers or more forceful steps by the agency to withdraw antibiotics from specific uses in animals, according to CVM director Stephen Sundloff. Critics of this plan argue, in part, that implementation could undermine efforts to protect the health of food animals and jeopardize the food supply. However, Sundloff warns, "Failure to reach agreement will only prolong a contentious debate which has lasted for more than 30 years." The CVM plan is part of a larger "Public Health Action Plan to Combat Antimicrobial Resistance" that was released by the Department of Health and Human Services (Washington, DC) shortly before President Clinton left office.

\section{UK therapeutic cloning delayed}

UK researchers can expect delays in receiving a license from the Human Fertility and Embryology Authority (London) to allow them to create cloned human embryos for stem-cell research (Nat. Biotechnol. 19, 97, 2001). The UK House of Lords on January 22 voted with a $70 \%$ majority to extend the Human Fertilisation and Embryology Act to allow therapeutic cloning. But an antiabortion group, ProLife Alliance, is suing the Secretary of State for Health at the UK High Court, seeking to overturn the decision. The group is calling for new primary legislation on the grounds that embryos created by cell nuclear replacement are not generated by "fertilization" and thus do not satisfy the definition of "embryo" in the Act and so cannot be covered by the newly extended law. As a result, instead of coming into force on 31 January, the extended law has been put on hold until the hearing, which is expected to take place on June 15 However, as Anne McLaren from the Wellcome/CRC Institute of Cancer and Developmental Biology (Cambridge, UK), points out, "An embryo is an embryo and I would be surprised if the judiciary review comes to another opinion." 